\title{
Numerical Analysis of Friction Effects on Temperature and Phases within Forged Ti-6Al-4V Alloy Aeroengine Drum
}

\author{
Shiyuan Luo ${ }^{1,2, *}$, Yongxin Jiang ${ }^{1,3}$, Kai Yan ${ }^{1,2}$, Guangming Zou ${ }^{1,2}$, Po Zhang ${ }^{1,2}$ and Fengping Yu 4 \\ 1 Key Laboratory of Metallurgical Equipment and Control Technology, Ministry of Education, School of \\ Machinery and Automation, Wuhan University of Science and Technology, Wuhan 430081, China; \\ yongxinjianga@outlook.com (Y.J.); yankaia@outlook.com (K.Y.); zouguangming@wust.edu.cn (G.Z.); \\ pozhang@wust.edu.cn (P.Z.) \\ 2 Hubei Key Laboratory of Mechanical Transmission and Manufacturing Engineering, School of Machinery and \\ Automation, Wuhan University of Science and Technology, Wuhan 430081, China \\ 3 Precision Manufacturing Institute, Wuhan University of Science and Technology, Wuhan 430081, China \\ 4 Technology Center, Wuxi Turbine Blade Co., Ltd., Wuxi 214174, China; yufengpingxhdx@163.com \\ * Correspondence: shiyuanluo@wust.edu.cn; Tel.: +86-27-6886-2283
}

Citation: Luo, S.; Jiang, Y.; Yan, K.; Zou, G.; Zhang, P.; Yu, F. Numerical Analysis of Friction Effects on Temperature and Phases within Forged Ti-6Al-4V Alloy Aeroengine Drum. Metals 2021, 11, 1649. https:// doi.org/10.3390/met11101649

Academic Editor: Samuel Chao Voon Lim

Received: 9 September 2021

Accepted: 14 October 2021

Published: 18 October 2021

Publisher's Note: MDPI stays neutral with regard to jurisdictional claims in published maps and institutional affiliations.

Copyright: (c) 2021 by the authors. Licensee MDPI, Basel, Switzerland. This article is an open access article distributed under the terms and conditions of the Creative Commons Attribution (CC BY) license (https:/ / creativecommons.org/licenses/by/ $4.0 /)$.

\begin{abstract}
Friction conditions significantly impact the temperature and phases of titanium forged parts, further directly affecting the microstructures and mechanical properties of final parts. In this paper, a 2D simplified finite element (FE) model combined with phase transition equations is developed to simulate a Ti-6Al-4V drum forging procedure. Then, friction effects on the temperature and phases of the forged drum are numerically analyzed and verified by experiments. The simulated results indicate that a reasonable range of friction factor is needed to obtain a relatively homogenous temperature distribution within the forged drum. Moreover, unlike its small influence on the $\alpha+\beta$ phase, improving friction obviously decreases the general levels of temperature and $\beta$ phase and increases the homogeneities of $\alpha$ and $\beta$ phases within the forged drum, which are associated with cooling rates and the heating effects of friction and deformation.
\end{abstract}

Keywords: titanium alloy; friction condition; drum forging; phase transition; FE modeling

\section{Introduction}

Titanium drums are crucial aeroengine components which have a significant influence on the reliability of aircrafts [1]. According to previous works, the forging of titanium aeronautic components is a difficult operation [2-4], and friction conditions greatly affect the temperature and phases of forged parts $[5,6]$, further impacting the corrosion resistance and fatigue life of final parts $[7,8]$. Hence, an investigation of friction effects on temperature and phases within titanium forged drums is of vital importance and urgent necessity to optimize their ultimate mechanical properties and service life.

Ti- $6 \mathrm{Al}-4 \mathrm{~V}$, including $\alpha$ and $\beta$ phases, is a representative dual phase titanium alloy [9]. Focusing on its phase transition behaviors, two predictive equations have been carried out. Hereinto, a simplified Avrami equation developed by Sha et al. [10] was used to identify the $\alpha \rightarrow \beta$ phase transition characteristics in a heating operation. In contrast, a JohnsonMehl-Avrami (JMA) equation established by Malinov et al. [11] was utilized to predict $\beta \rightarrow \alpha+\beta$ phase transition behaviors in a cooling operation. Moreover, embedding the above equations into 2D FE approaches, Pan et al. [12] predicted machining-induced phase transition in Ti-6Al-4V cutting procedures. Quan et al. [13] studied the phase transition characteristics of a Ti-6Al-4V cylinder during the non-isothermal upsetting procedure. Ducato et al. [14] simulated phase transition of a U-shaped Ti-6Al-4V workpiece in the hot forging procedure. Bruschi et al. [15] revealed the phase transition behaviors of a Ti-6Al-4V blade section in the hot forging operation. Luo et al. [16] reported the phase transition characteristics of a Ti-6Al-4V drum during hot forging and subsequent cooling operations. 
Furthermore, based on 3D FE approaches, Mi et al. [17] predicted the phase transition characteristics in a Ti-6Al-4V alloy welding operation. Ducato et al. [18] reflected the phase transition behaviors in a Ti-6Al-4V flange hot forging procedure. Buffa et al. [19] studied Ti-6Al-4V phase distributions during a welding process and verified the simulated results with experiments. Luo et al. [20] revealed the phase transition behaviors of a large Ti-6Al$4 \mathrm{~V}$ turbine blade during the hot forging operation. Note that, although plenty of studies have been performed, none of them are tied to friction effects on the temperature and phase of Ti-6Al-4V drums, particularly on their general levels and distribution uniformities.

Consequently, the aim of this paper is to investigate the influences of friction conditions on the temperature and phases within a Ti-6Al-4V aeroengine drum in the forging procedure. For this purpose, a 2D simplified FE model combined with phase transition equations is established by DEFORM software. Then, based on two evaluation indexes, friction effects on the temperature and phase transition characteristics of the forged drum are analyzed quantitatively. Finally, experiments are conducted to demonstrate the validation of the simulated results. This work can provide guidance for the process optimization, further improving the mechanical properties and service life of Ti-6Al-4V drums.

\section{FE Modeling}

Owing to the axisymmetric structure of drums described in Figure 1a, a 2D simplified FE model is developed to simulate their forging procedure $[13,16]$, as shown in Figure $1 \mathrm{~b}$. Hereinto, the deformation of the workpiece is restricted to the $\mathrm{X}-\mathrm{Z}$ plane and the movements of the workpiece and forging dies at the rotatory central line in $\mathrm{x}$ negative direction are restricted. Moreover, for the workpiece, heat exchange with the environment is defined on all faces (pink lines) except the central line. Furthermore, there are about 8000 and 4000 quadrilateral elements used for the workpiece and forging dies, with mesh details described in Figure 1c.

(a)

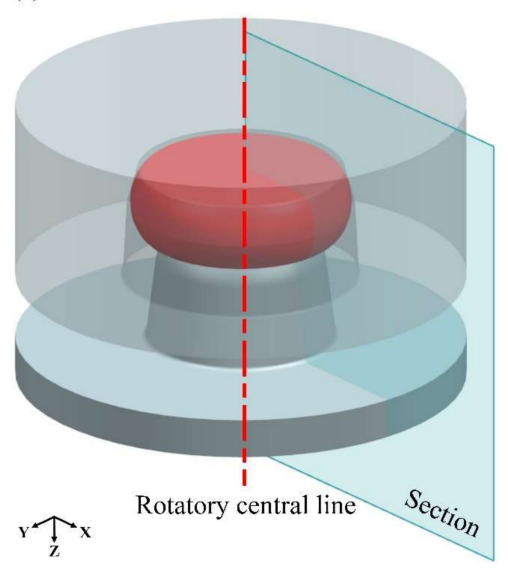

(b)

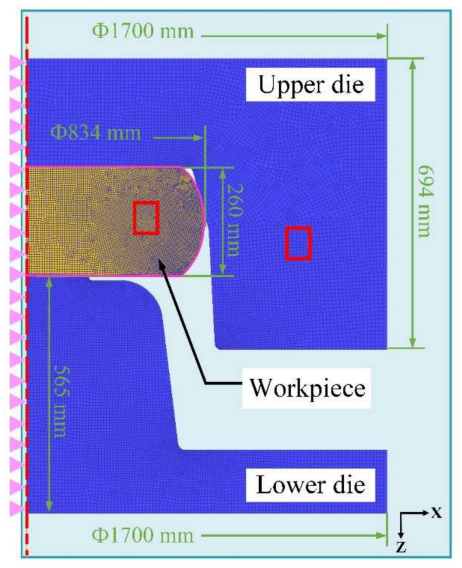

(c)

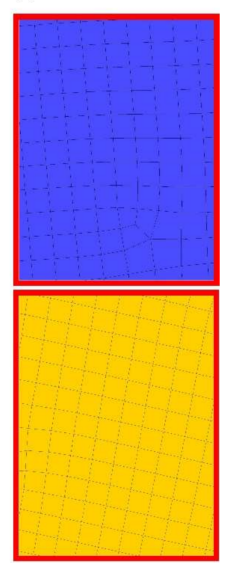

Figure 1. (a) Drum structure, (b) 2D simplified FE model, and (c) the mesh details of dies and workpiece.

Moreover, the material of the workpiece is Ti-6Al-4V alloy, with stress-strain curves shown in [21]. Its heat capacity $(C)$ and thermal conductivity $(K)$ are described by Equations (1) and (2) [22]. The material of dies is AISI H13 tool steel with above two material parameters as shown in [23].

$$
\begin{gathered}
C=2.36+3 \times 10^{-4} \times T+2 \times 10^{-6} \times T^{2} \\
K=0.0131 \times T+6.45
\end{gathered}
$$


Then, the simplified Avrami and JMA equations are, respectively, used to predict the phase transition percentages of $\alpha \rightarrow \beta$ and $\beta \rightarrow \alpha+\beta$, corresponding to the heating and cooling processes. The above two equations are given below [15]:

$$
\begin{gathered}
f_{v(\alpha \rightarrow \beta)}=1-\exp \left\{A\left[\left(T-T_{S}\right) /\left(T_{e}-T_{S}\right)\right]^{D}\right\} \\
f_{v(\beta \rightarrow \alpha+\beta)}=1-\exp \left(-b t^{n}\right)
\end{gathered}
$$

where $f_{v(\alpha \rightarrow \beta)}$ and $f_{v(\beta \rightarrow \alpha+\beta)}$, respectively, denote the transformed percentage of $\beta$ and $\alpha+\beta$ phases, $T$ means the instantaneous temperature, $T_{e}=980{ }^{\circ} \mathrm{C}$ and $T_{s}=600{ }^{\circ} \mathrm{C}$ are the ending and starting temperatures of phase transformation, $A=-1.86$ and $D=4.35$ are material constants [20], $t$ is the cooling time, $n=1.35$ is the Avrami index [16], and $b$ is the coefficient decided by the time-temperature-transformation (TTT) start curve [15].

Furthermore, to describe frictional stress $(\tau)$ in the drum forging procedure, a shear friction model is employed [24].

$$
\tau=m k
$$

where $m$ represents the friction factor and $k$ denotes the shear stress.

Finally, the critical parameters of materials and the hot forging procedure are listed in Table 1. Further, to better present the distributions of temperature and phases within the forged drum, the 2D simulated results are transformed into 3D ones by using the postprocessor of DEFORM-2 ${ }^{\mathrm{TM}} \mathrm{V10.2}$, which is developed by American scientific forming

\begin{tabular}{|c|c|c|}
\hline Parameters & Workpiece & Dies \\
\hline Material & Ti-6Al-4V & AISI H13 \\
\hline Heat capacity $\left(\mathrm{N} /\left(\mathrm{mm}^{2}{ }^{\circ} \mathrm{C}\right)\right)$ & Equation (1) & [23] \\
\hline Thermal conductivity $\left(\mathrm{N} /\left(\mathrm{s}^{\circ} \mathrm{C}\right)\right)$ & Equation (2) & [23] \\
\hline Emissivity & $0.7[25]$ & $0.7[26]$ \\
\hline Convection coefficient $\left(\mathrm{N} /\left(\mathrm{s} \mathrm{mm}{ }^{\circ} \mathrm{C}\right)\right)$ & $0.02[27]$ & $0.02[28]$ \\
\hline Heat transfer coefficient $\left(\mathrm{N} /\left(\mathrm{s} \mathrm{mm}{ }^{\circ} \mathrm{C}\right)\right)$ & \multicolumn{2}{|c|}{5 [22] } \\
\hline Initial workpiece temperature $\left({ }^{\circ} \mathrm{C}\right)$ & \multicolumn{2}{|c|}{930} \\
\hline Initial die temperature $\left({ }^{\circ} \mathrm{C}\right)$ & \multicolumn{2}{|c|}{250} \\
\hline Environment temperature $\left({ }^{\circ} \mathrm{C}\right)$ & \multicolumn{2}{|c|}{20} \\
\hline Forging stroke $(\mathrm{mm})$ & \multicolumn{2}{|c|}{210} \\
\hline Forging velocity (mm/s) & \multicolumn{2}{|c|}{300} \\
\hline Friction factor & \multicolumn{2}{|c|}{$0.1 / 0.2 / 0.3 / 0.4 / 0.5 / 0.6$} \\
\hline
\end{tabular}
technologies corporation (Columbus, OH, USA) [16].

Table 1. The critical thermal parameters of materials and hot forging procedure.

\section{Results and Discussion}

\subsection{Evaluation Indexes}

For temperature, its average $\left(T_{a v g}\right)$ and standard deviation $\left(T_{s d}\right)$ values are selected to quantitatively reflect the variations of its general level and distribution uniformity, which are defined as [20]:

$$
\begin{gathered}
T_{a v g}=\sum_{i}^{N} T_{i} / N \\
T_{s d}=\sqrt{\sum_{i}^{N}\left(T_{i}-T_{a v g}\right)^{2} /(N-1)}
\end{gathered}
$$

where $N$ represents the total quantity of elements, and $T_{i}$ means the temperature of element $i$.

Moreover, for the $\alpha$ phase, its average volume fraction $\left(f_{\text {avg }}(\alpha)\right)$ and standard deviation $\left(f_{s d}(\alpha)\right)$ values are obtained by [6]: 


$$
\begin{gathered}
f_{a v g}(\alpha)=\sum_{i}^{N} f_{i}(\alpha) / N \\
f_{s d}(\alpha)=\sqrt{\sum_{i}^{N}\left(f_{i}(\alpha)-f_{a v g}(\alpha)\right)^{2} /(N-1)}
\end{gathered}
$$

where $f_{i}(\alpha)$ represents the $\alpha$ phase volume fraction of element $i$. Additionally, similar equations are employed for $\beta$ and $\alpha+\beta$ phases.

\subsection{Friction Effects on Temperature within Forged Drum}

Figure $2 \mathrm{a}$ presents the variation range of temperature and friction effects on the maximal and minimal values $\left(T_{\max }\right.$ and $T_{\min }$ ) of the forged drum. Hereinto, the $T_{\max }$ increases from $997^{\circ} \mathrm{C}$ to $1160{ }^{\circ} \mathrm{C}$, and the $T_{\min }$ decreases from $754{ }^{\circ} \mathrm{C}$ to $692{ }^{\circ} \mathrm{C}$ with the increment of $m$ from 0.1 to 0.6 . These can be owing to the heating effects of friction and deformation. Specifically, as friction is enhanced, the friction heating effect is strengthened, further leading to an obvious increment of heat generation within the internal wall area of the forged drum. In contrast, the intensive friction weakens the deformation heating effect within hard deformation areas, thereby resulting in a decrement of heat generation within the bottom area of the forged drum illustrated in Figure 3. This view can be indirectly sustained by our previous work [6]. Moreover, as shown in Figure 2b, unlike the slight increment of $T_{\text {avg }}$, the value of $T_{s d}$ first dramatically drops, and then gradually increases from the level of $24{ }^{\circ} \mathrm{C}$ as the $m$ exceeds 0.3 . This finding indicates that a reasonable range of friction conditions exists, which leads to a homogeneous distribution of temperature within the forged drum, as described in Figure 3.

(a)

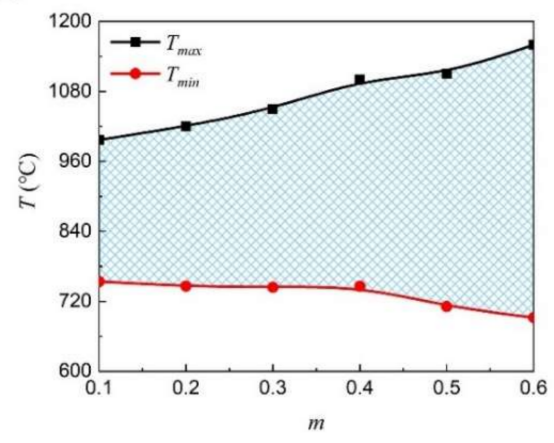

(b)

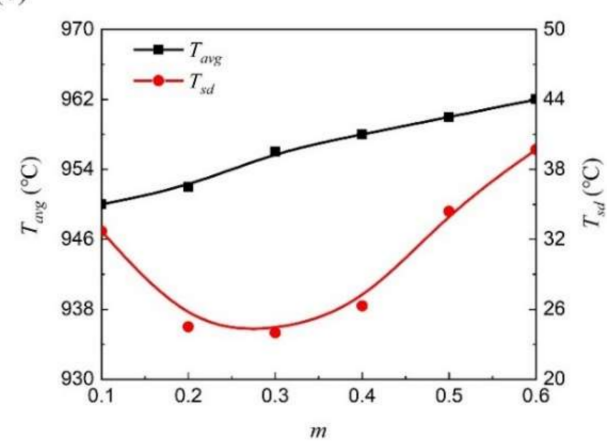

Figure 2. (a) $T_{\max }$ and $T_{\min }$ as well as (b) $T_{a v g}$ and $T_{s d}$ variations with the increment of $m$.
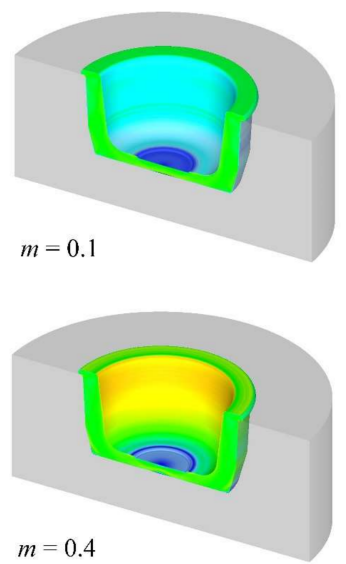

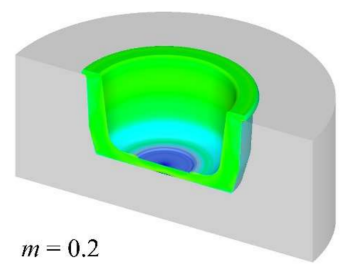

m.2

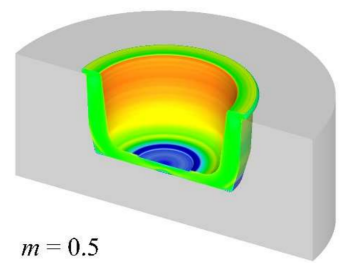

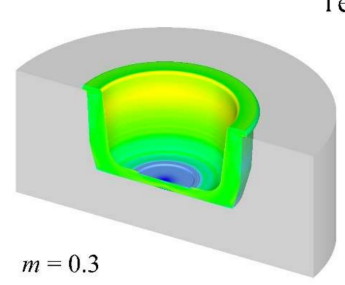

Temperature $\left({ }^{\circ} \mathrm{C}\right)$

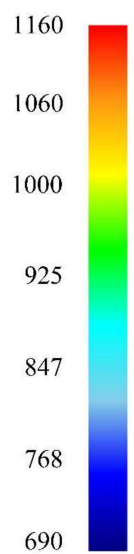

Figure 3. Distributions of temperature under various friction conditions. 


\subsection{Friction Effects on Phases within Forged Drum}

\subsection{1. $\alpha$. Phase Evolution and Distribution}

Figure 4 a presents the variation range of equiaxed $\alpha$ phase volume fraction and friction effects on its maximal and minimal values $\left(f_{\max }(\alpha)\right.$ and $\left.f_{\min }(\alpha)\right)$ within the forged drum. It can be found that the $f_{\max }(\alpha)$ remains unchanged (about 36.5\%) with the increment of $m$. This is because the phase transition behavior from $\beta$ to equiaxed $\alpha$ phases only occurs when cooling rates are less than $0.03^{\circ} \mathrm{C} / \mathrm{s}$. This explanation can be sustained by previous studies $[29,30]$, which reported that a relatively low cooling rate can promote the nucleation of subgrains, resulting in the occurrence of static recrystallization and more homogenous microstructures. Moreover, the $f_{\min }(\alpha)$ decreases from $12 \%$ to $0.6 \%$ with the increment of $\mathrm{m}$ from 0.1 to 0.6 . This phenomenon is ascribed to the $\alpha \rightarrow \beta$ phase transition prompted by the strengthening of $T_{\max }$, as plotted in Figure 2a. Then, as shown in Figure $4 \mathbf{b}$, the $f_{\text {avg }}(\alpha)$ decreases from $24.5 \%$ to $21.5 \%$ with the increment of $m$ from 0.1 to 0.6 . This result is highly consistent with the evolutions of $f_{\max }(\alpha)$ and $f_{\min }(\alpha)$, which can be related to the increment of $T_{\text {avg }}$ presented in Figure $2 \mathrm{~b}$. Conversely, $f_{s d}(\alpha)$ generally increases from $4.94 \%$ to $6.56 \%$ as the $m$ is enhanced from 0.1 to 0.6 . This result reveals that the $\alpha$ phase distribution becomes more homogenous as improving friction conditions, as described in Figure 5.

(a)

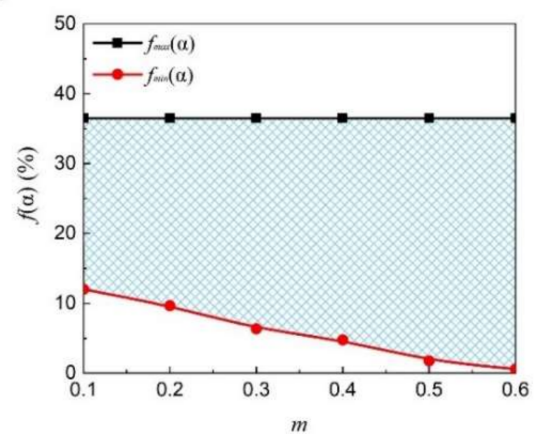

(b)

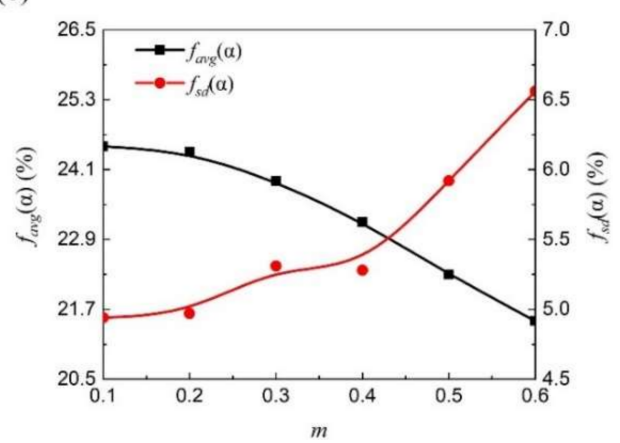

Figure 4. (a) $f_{\max }(\alpha)$ and $f_{\min }(\alpha)$ as well as $(\mathbf{b}) f_{a v g}(\alpha)$ and $f_{s d}(\alpha)$ variations with the increment of $m$.
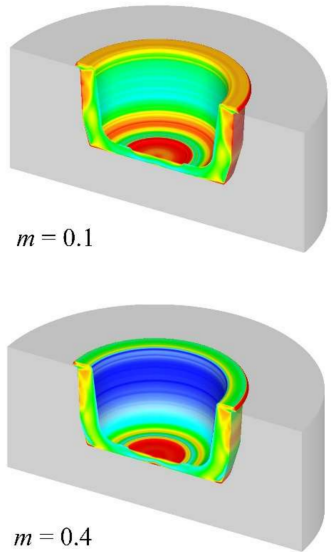

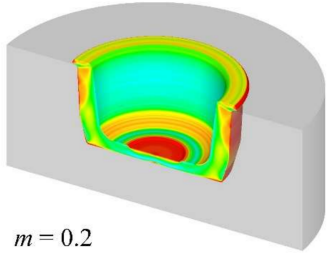

$m=0.2$

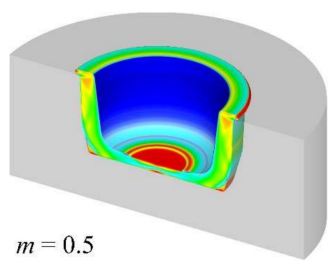

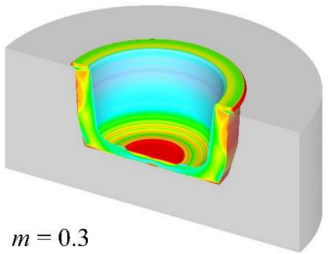

$m=0.3$

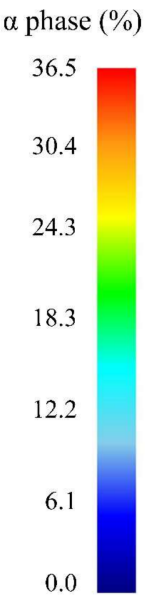

Figure 5. Distributions of $\alpha$ phase under various friction conditions.

\subsection{2. $\beta$. Phase Evolution and Distribution}

Figure 6a presents the variation range of equiaxed $\beta$ phase volume fraction and friction effects on its maximal and minimal values $\left(f_{\max }(\beta)\right.$ and $\left.f_{\min }(\beta)\right)$ within the forged drum. Unlike $f_{\min }(\alpha)$, the $f_{\max }(\beta)$ shows an opposite evolution, which increases from $88 \%$ to $99.5 \%$ as $m$ is enhanced from 0.1 to 0.6 . The above phenomenon is also owing to the $\alpha \rightarrow \beta$ phase transition influenced by the heating effects of friction and deformation, as mentioned in Section 3.3.1. Moreover, it can be found that the $f_{\min }(\beta)$ stays unchanged (about $63.5 \%$ ) and 
presents good consistency with the evolution of $f_{\max }(\alpha)$ described in Figure 4a. Then, as shown in Figure $6 \mathrm{~b}$, the $f_{\text {avg }}(\beta)$ rises from $75.3 \%$ to $78.5 \%$ with the increment of $m$, which is related to the strengthening of $T_{\text {avg }}$ illustrated in Figure $2 \mathrm{~b}$. Besides, the $f_{s d}(\beta)$ increases from $4.94 \%$ to $6.56 \%$ as the $m$ is increased from 0.1 to 0.6 , showing the same evolution with $f_{s d}(\alpha)$. This result indicates that the $\beta$ phase distribution is more homogenous with a good lubricated condition, as described in Figure 7.

(a)

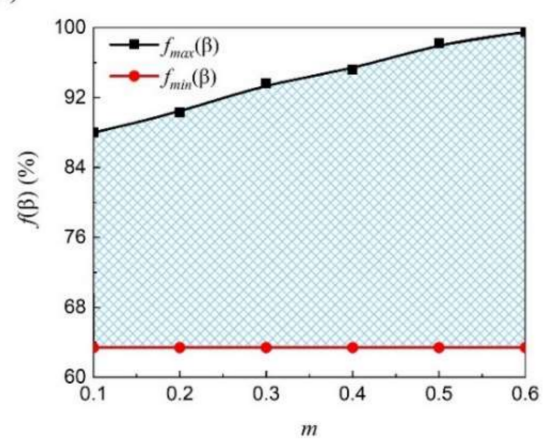

(b)

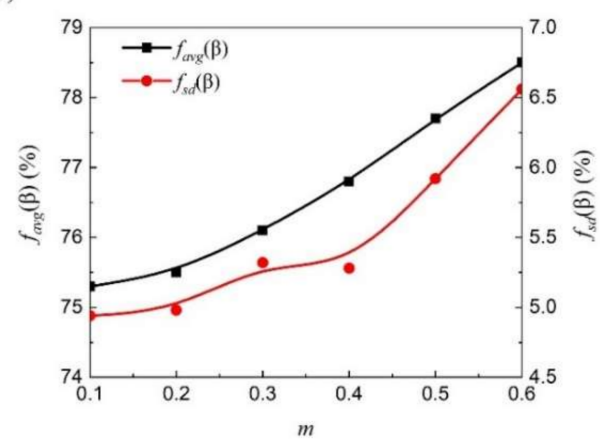

Figure 6. (a) $f_{\max }(\beta)$ and $f_{\min }(\beta)$ as well as $(\mathbf{b}) f_{a v g}(\beta)$ and $f_{s d}(\beta)$ variations with the increment of $m$.

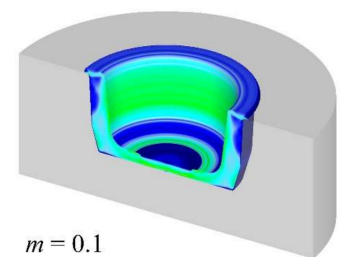

$$
m=0.1
$$

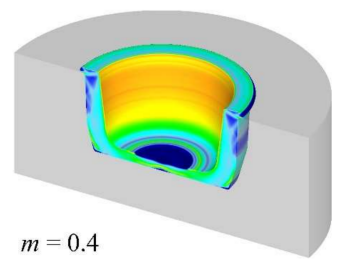

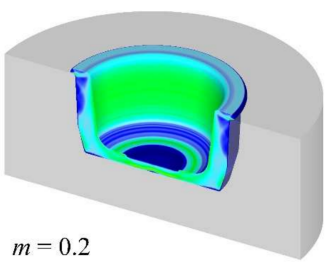

$m=0.2$

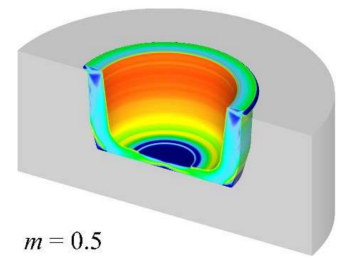

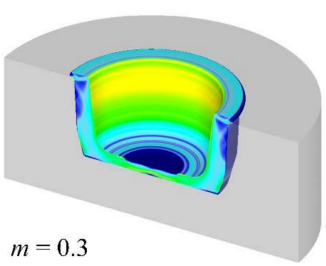

$m=0.3$

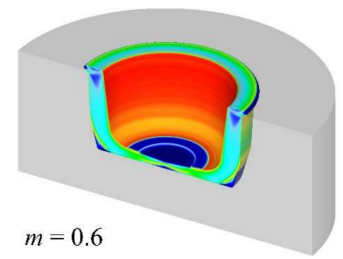

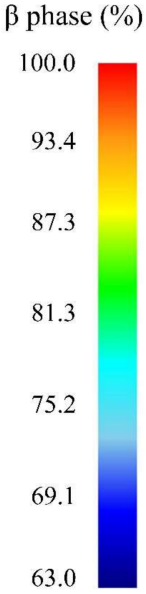

Figure 7. Distributions of $\beta$ phase under various friction conditions.

\subsection{3. $\alpha+\beta$. Phase Evolution and Distribution}

Figure 8 a presents the variation range of lamellar $\alpha+\beta$ phase volume fraction and friction effects on its maximal and minimal values $\left(f_{\max }(\alpha+\beta)\right.$ and $\left.f_{\min }(\alpha+\beta)\right)$ within the forged drum. Distinct from $\alpha$ and $\beta$ phases, the volume fraction of $\alpha+\beta$ phase is dozens of times smaller, and both values of $f_{\max }(\alpha+\beta)$ and $f_{\min }(\alpha+\beta)$ (about $0.06 \%$ and $0 \%$ ) remain basically unchanged with the increment of $m$. This finding suggests that friction has little effect on the $\beta \rightarrow \alpha+\beta$ phase transition within the forged drum. These phenomena are ascribed as the reason that the large forging velocity $(300 \mathrm{~mm} / \mathrm{s})$ shortens the forging time $(0.7 \mathrm{~s})$, further limiting the phase transition time, and thereby causing a tiny volume fraction of the $\alpha+\beta$ phase. This view can be proved by the investigation of Pan et al. [12], which described in detail the time-temperature-transformation curves of titanium alloy. Moreover, as shown in Figure 8b, both values of $f_{\text {avg }}(\alpha+\beta)$ and $f_{s d}(\alpha+\beta)$ can also be considered to maintain invariability with the increment of $m$, corresponding to about $0.004 \%$ and $0.01 \%$, respectively. This result suggests that the distribution of the $\alpha+\beta$ phase is more homogenous than the ones of $\alpha$ and $\beta$ phases, as presented in Figure 9. 
(a)

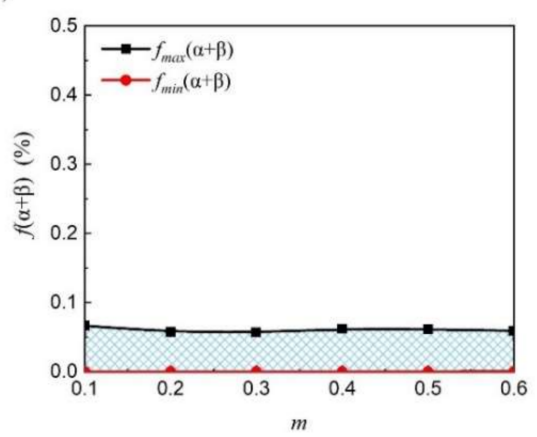

(b)

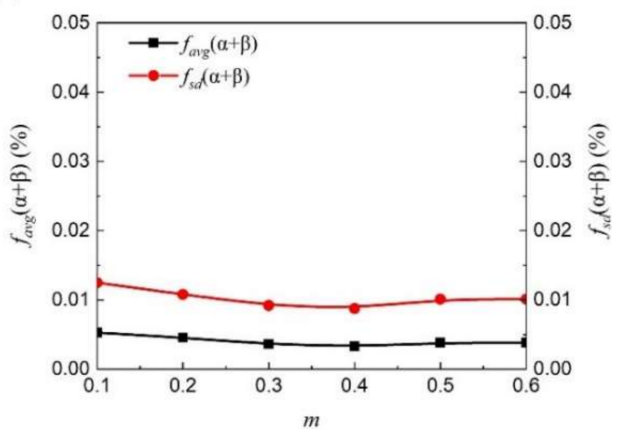

Figure 8. (a) $f_{\max }(\alpha+\beta)$ and $f_{\min }(\alpha+\beta)$ as well as $(\mathbf{b}) f_{\text {avg }}(\alpha+\beta)$ and $f_{s d}(\alpha+\beta)$ variations with the increment of $m$.
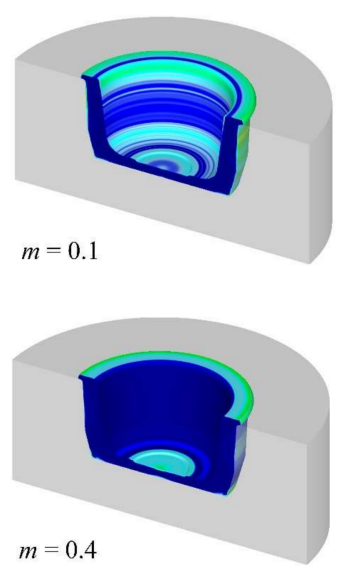
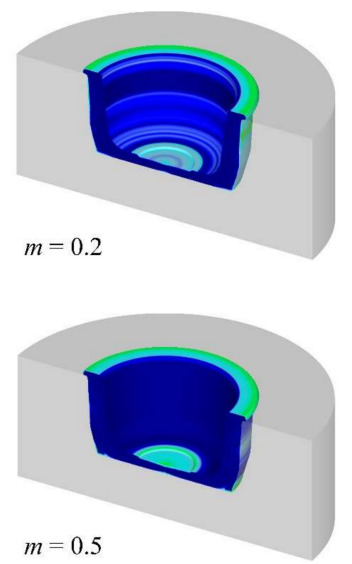

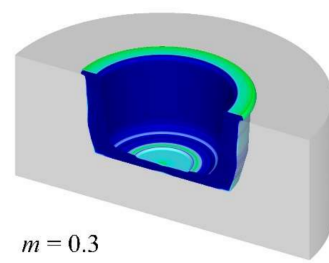

$\alpha+\beta$ phase $(\%)$

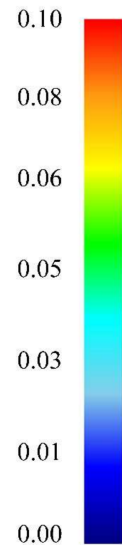

Figure 9. Distributions of $\alpha+\beta$ phase under various friction conditions.

\section{Experimental Verification}

Figure 10a presents the glass lubricant-assisted hot drum forging experiments with the forging parameters described in Table 1 . For Ti-6Al-4V alloy, the friction factor under the glass lubricant condition is about 0.3 , according to the work of Zhu et al. [31]. Figure $10 \mathrm{~b}$ shows the simulated result with the same forging parameters. It can be seen from Table 2 that the experimental and simulated geometries, including internal and external dimensions $(h, d, H$, and $D)$, present good agreement with errors less than the allowed error margin (2\%). Then, after a two-hour air cooling operation, the microstructures at the bottom $\left(P_{1}\right)$ and flash $\left(P_{2}\right)$ areas of the cooled drum are observed as displayed in Figure 10c, which mainly consist of $\alpha$ and $\alpha+\beta$ phases. Finally, due to the fact that the volume fraction of equiaxed $\alpha$ phase remains unchanged after air cooling process, the volume fraction of simulated equiaxed $\alpha$ phase within the forged drum is compared with the experimental one of the cooled drum. It can be found from Figure $10 \mathrm{~d}$ that the simulated $\alpha$ phase volume fractions qualitatively agree with the experimental ones, showing errors less than 7.6\%. Therefore, the 2D FE model and its simulation results are effective. 


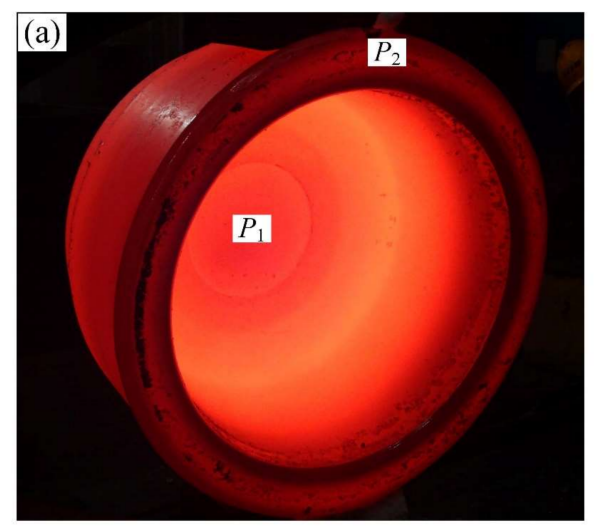

(b) !
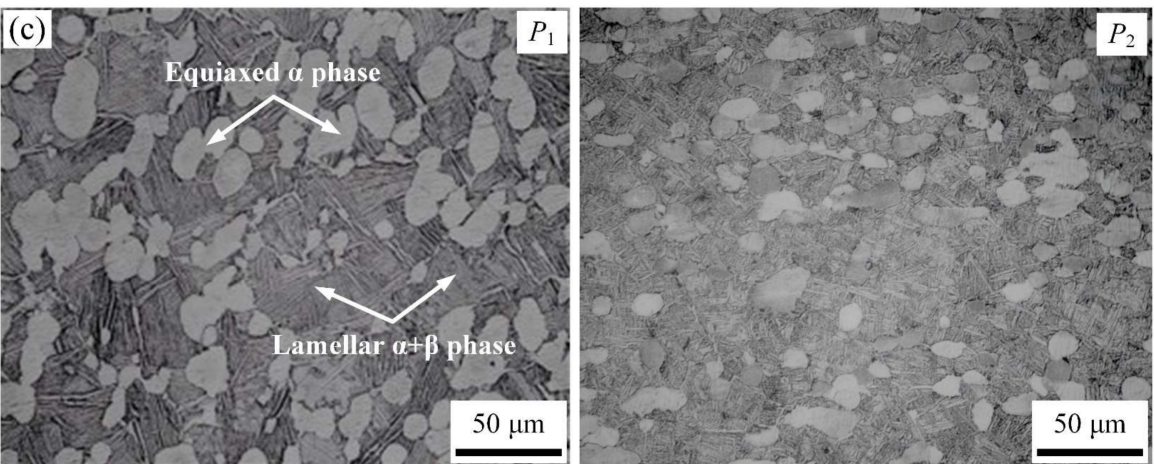

(d)

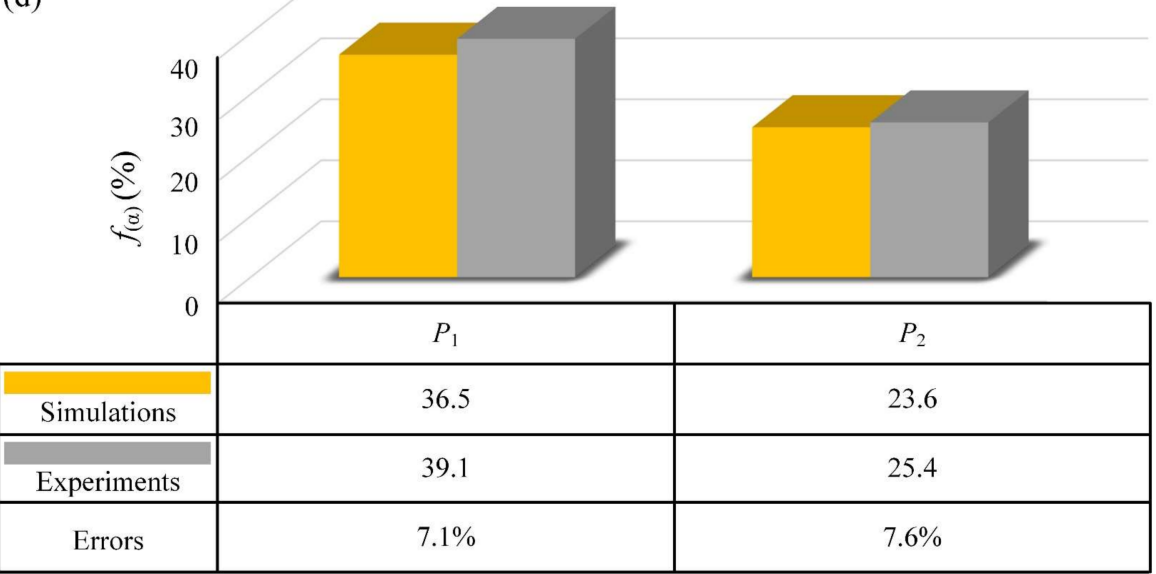

Figure 10. (a) Experimental, (b) simulated drums, (c) microstructures, and (d) the $\alpha$ phase volume fractions of experimental and simulated results.

Table 2. The critical parameters of materials and hot forging procedure.

\begin{tabular}{ccccc}
\hline \multirow{2}{*}{ Parameters } & \multicolumn{4}{c}{ Mean Values $(\mathbf{m m})$} \\
\cline { 2 - 5 } & $\boldsymbol{h}$ & $\boldsymbol{d}$ & $\boldsymbol{H}$ & $\boldsymbol{D}$ \\
\hline Experimental results & 415.5 & 284.6 & 453.7 & 905.6 \\
Simulated results & 414.3 & 283.2 & 455.1 & 907.9 \\
Errors & $0.29 \%$ & $0.53 \%$ & $0.22 \%$ & $0.24 \%$ \\
\hline
\end{tabular}

\section{Conclusions}

(1) Unlike the decrement of $T_{\min }$, the values of $T_{\max }$ and $T_{\text {avg }}$ increase with the increment of $m$, which is related to the heating effects of friction and deformation. Moreover, the value of $T_{s d}$ first dramatically drops, and then gradually increases as the $m$ exceeds 
0.3. This finding indicates that a reasonable range of friction is exists to obtain a more homogenous temperature distribution in the forged drum.

(2) Different from the invariable $f_{\max }(\alpha)$, the values of $f_{\min }(\alpha)$ and $f_{\text {avg }}(\alpha)$ decrease with the increment of $m$, which are ascribed to the $\alpha \rightarrow \beta$ phase transition prompted by the increments of $T_{\max }$ and $T_{\text {avg }}$. Moreover, the value of $f_{s d}(\alpha)$ presents an inverse evolution, which indicates that the $\alpha$ phase distribution of the forged drum becomes more inhomogeneous with a poor lubricated condition.

(3) In contrast to the $\alpha$ phase, the values of $f_{\max }(\beta)$ and $f_{\min }(\beta)$ reveal an opposite evolution as friction is enhanced, which is associated with the variations of temperature and cooling rates. Moreover, both values of $f_{\text {avg }}(\beta)$ and $f_{s d}(\beta)$ increase with the increment of $m$. This finding indicates that $\beta$ phase distribution of the forged drum becomes more homogenous as friction conditions improve.

(4) Compared with $\alpha$ and $\beta$ phases, the volume fraction of the $\alpha+\beta$ phase is much smaller, and the values of $f_{\max }(\alpha+\beta), f_{\min }(\alpha+\beta), f_{\text {avg }}(\alpha+\beta)$, and $f_{s d}(\alpha+\beta)$ can be regarded as constants with the increment of $\mathrm{m}$. These findings indicate that the $\beta \rightarrow \alpha+\beta$ phase transition hardly occurs in the drum forging operation, owing to the short phase transition time decided by high forging velocity.

Author Contributions: Conceptualization, S.L. and Y.J.; methodology, S.L.; software, K.Y.; validation, F.Y., G.Z. and P.Z.; formal analysis, S.L.; investigation, Y.J.; resources, S.L.; data curation, G.Z.; writing—original draft preparation, S.L.; writing—review and editing, S.L., G.Z. and P.Z.; visualization, F.Y.; supervision, P.Z.; project administration, S.L.; funding acquisition, S.L. All authors have read and agreed to the published version of the manuscript.

Funding: This research was funded by the Hubei Provincial Natural Science Foundation of China with grant number 2020CFB115.

Data Availability Statement: Not applicable.

Conflicts of Interest: The authors declare no conflict of interest.

\section{References}

1. Li, C.F.; Miao, B.Q.; Tang, Q.S.; Xi, C.Y.; Wen, B.C. Nonlinear vibrations analysis of rotating drum-disk coupling structure. J. Sound. Vib. 2018, 420, 35-60.

2. Lin, Y.C.; Huang, J.; He, D.G.; Zhang, X.Y.; Wu, Q.; Wang, L.H.; Chen, C.; Zhou, K.C. Phase transformation and dynamic recrystallization behaviors in a Ti55511 titanium alloy during hot compression. J. Alloys Compd. 2019, 795, 471-482. [CrossRef]

3. Luo, S.Y.; Zhu, D.H.; Qian, D.S.; Hua, L.; Yan, S.J.; Zhang, J.J. Effects of friction model on forging process of Ti-6Al-4V turbine blade considering the influence of sliding velocity. Int. J. Adv. Manuf. Technol. 2016, 82, 1993-2002. [CrossRef]

4. Zhu, D.H.; Feng, X.Z.; Xu, X.H.; Yang, Z.Y.; Li, W.L.; Yan, S.J.; Ding, H. Robotic grinding of complex components: A step towards efficient and intelligent machining-challenges, solutions, and applications. Robot. Comput. Integr. Manuf. 2020, 65, 101908. [CrossRef]

5. Serebriakov, I.; Cabrera, E.S.P.; Dubar, L.; Moreau, P.; Meresse, D.; Sosa, J.G.L.B. Friction analysis during deformation of steels under hot-working conditions. Tribol. Int. 2021, 158, 106928. [CrossRef]

6. Luo, S.Y.; Wang, Q.; Zhang, P.; Li, J.; Liu, Q.L. Effect of friction conditions on phase transformation characteristics in hot forging process of Ti-6Al-4V turbine blade. J. Mater. Res. Technol. 2020, 9, 2107-2115. [CrossRef]

7. Ji, R.J.; Wang, H.Y.; Wang, B.K.; Jin, H.; Liu, Y.H.; Cheng, W.H.; Cai, B.P.; Li, X.P. Removing loose oxide layer and producing dense $\alpha$-phase layer simultaneously to improve corrosion resistance of Ti-6Al-4V titanium alloy by coupling electrical pulse and ultrasonic treatment. Surf. Coat. Technol. 2020, 384, 125329. [CrossRef]

8. Shao, H.; Cai, L.L.; Wang, K.X.; Li, L.; Zhang, G.J.; Zhao, Y.Q. Microstructure and high strength-ductility synergy of Ti-6Al-4V alloy induced by joule heat treatment. J. Mater. Sci. 2018, 53, 16609-16617. [CrossRef]

9. Dai, J.H.; Xia, J.Y.; Chai, L.J.; Murty, K.L.; Guo, N.; Daymond, M.R. Correlation of microstructural, textural characteristics and hardness of Ti-6Al-4V sheet $\beta$-cooled at different rates. J. Mater. Sci. 2020, 55, 8346-8362. [CrossRef]

10. Sha, W.; Savko, M. Titanium Alloys: Modelling of Microstructure, Properties and Applications; Woodhead Publishing Limited and CRC Press: Cambridge, UK, 2009; pp. 203-235.

11. Malinov, S.; Markovsky, P.; Sha, W.; Guo, Z. Resistivity study and computer modelling of the isothermal transformation kinetics of Ti-6Al-4V and Ti-6Al-2Sn-4Zr-2Mo-0.08Si alloys. J. Alloys Compd. 2001, 314, 181-192. [CrossRef]

12. Pan, Z.P.; Liang, S.Y.; Garmestani, H.; Shih, D.S. Prediction of machining-induced phase transformation and grain growth of Ti-6Al-4V alloy. Int. J. Adv. Manuf. Technol. 2016, 87, 859-866. [CrossRef] 
13. Quan, G.Z.; Pan, J.; Zhang, Z.H. Phase transformation and recrystallization kinetics in space-time domain during isothermal compressions for Ti-6Al-4V analyzed by multi-field and multi-scale coupling FEM. Mater. Des. 2016, 94, 523-535. [CrossRef]

14. Ducato, A.; Frantini, L.; Micari, F. Prediction of phase transformation of Ti-6Al-4V titanium alloy during hot-forging processes using a numerical model. Proc. Inst. Mech. Eng. L 2014, 228, 154-159. [CrossRef]

15. Bruschi, S.; Buffa, G.; Ducato, A.; Fratini, L.; Ghiotti, A. Phase evolution in hot forging of dual phase titanium alloys: Experiments and numerical analysis. J. Manuf. Process. 2015, 20, 382-388. [CrossRef]

16. Luo, S.Y.; Yao, J.N.; Zou, G.M.; Li, J.; Jiang, J.; Yu, F.P. Transformation characteristics of temperature and phases within Ti-6Al-4V aeroengine drum in hot forging and air cooling procedures. J. Mater. Res. Technol. 2020, 9, 8235-8244. [CrossRef]

17. Mi, G.Y.; Wei, Y.H.; Zhan, X.H.; Gu, C.; Yu, F.Y. A coupled thermal and metallurgical model for welding simulation of Ti-6Al-4V alloy. J. Mater. Process. Technol. 2014, 214, 2434-2443. [CrossRef]

18. Ducato, A.; Buffa, G.; Fratini, L.; Shivpuri, R. Dual phase titanium alloy hot forging process design: Experiments and numerical modeling. Adv. Manuf. 2015, 3, 269-281. [CrossRef]

19. Buffa, G.; Ducato, A.; Fratini, L. FEM based prediction of phase transformations during friction stir welding of Ti6Al4V titanium alloy. Mater. Sci. Eng. A 2013, 581, 56-65. [CrossRef]

20. Luo, S.Y.; Li, J.; Yu, F.P. Numerical analysis of phase transformation characteristics in hot forging and subsequent air cooling processes of Ti-6Al-4V turbine blade. Int. J. Adv. Manuf. Technol. 2020, 106, 1521-1532. [CrossRef]

21. Sente Software Ltd. JMatPro Demo Version; Sente Software Ltd.: Surrey, UK, 2015.

22. Alimirzaloo, V.; Sadeghi, M.H.; Biglari, F.R. Optimization of the forging of aerofoil blade using the finite element method and fuzzy-Pareto based genetic algorithm. J. Mech. Sci. Technol. 2012, 26, 1801-1810. [CrossRef]

23. Hu, H.J.; Huang, W.J. Studies on wears of ultrafine-grained ceramic tool and common ceramic tool during hard turning using Archard wear model. Int. J. Adv. Manuf. Technol. 2013, 69, 31-39. [CrossRef]

24. Luo, S.Y.; Yao, J.N.; Li, J.; Du, H.; Liu, H.Y.; Yu, F.P. Influence of forging velocity on temperature and phases of forged Ti-6Al-4V turbine blade. J. Mater. Res. Technol. 2020, 9, 12043-12051. [CrossRef]

25. Lu, X.F.; Lin, X.; Chiumenti, M.; Cervera, M.; Hu, Y.L.; Ji, X.L.; Ma, L.; Huang, W.D. In situ measurements and thermos-mechanical simulation of Ti-6Al-4V laser solid forming processes. Int. J. Mech. Sci. 2019, 153-154, 119-130. [CrossRef]

26. Zhou, W.B.; Lin, J.G.; Dean, T.A.; Wang, L.L. Feasibility studies of a novel extrusion process for curved profiles: Experimentation and modelling. Int. J. Mach. Tools. Manuf. 2018, 126, 27-43. [CrossRef]

27. Ren, J.X.; Cai, J.; Zhou, J.H.; Shi, K.N.; Li, X.Y. Inverse determination of improved constitutive equation for cutting titanium alloy Ti-6Al-4V based on finite element analysis. Int. J. Adv. Manuf. Technol. 2018, 97, 3671-3682. [CrossRef]

28. Bai, S.W.; Fang, G.; Zhou, J. Integrated physical and numerical simulations of weld seam formation during extrusion of magnesium alloy. J. Mater. Process. Technol. 2019, 266, 82-95. [CrossRef]

29. Dabrowski, R. The kinetics of phase transformations during continuous cooling of the Ti6Al4V alloy from the single-phase $\beta$ range. Arch. Metall. Mater. 2011, 56, 703-707. [CrossRef]

30. Lin, Y.C.; Tang, Y.; Zhang, X.Y.; Chen, C.; Yang, H.; Zhou, K.C. Effects of solution temperature and cooling rate on microstructure and micro-hardness of a hot compressed Ti-6Al-4V alloy. Vacuum 2019, 159, 191-199. [CrossRef]

31. Zhu, Y.C.; Zeng, W.D.; Ma, X.; Tai, Q.G.; Li, Z.H.; Li, X.G. Determination of the friction factor of Ti-6Al-4V titanium alloy in hot forging by means of ring-compression test using FEM. Tribol. Int. 2011, 44, 2074-2080. [CrossRef] 